\title{
Synthesis of Polymers in Aqueous Solutions. Synthesis of Polyesters by Reactions of Dicarboxylic Acids with Alkylene Dihalides Using 1,8-Diazabicyclo[5.4.0] undec-7-ene in Aqueous Solutions
}

\author{
Youji Yamada, Atsushi Kameyama, and Tadatomi Nishikubo ${ }^{\dagger}$ \\ Department of Applied Chemistry, Faculty of Engineering, Kanagawa University, \\ Rokkakubashi, Kanagawa-ku, Yokohama 221, Japan
}

(Received March 19, 1997)

\begin{abstract}
The polycondensation of adipic acid with $m$-xylylene dibromide was performed using 1,8-diazabicyclo[5.4.0] undec-7-ene (DBU) as a base in mixtures of dimethyl sulfoxide (DMSO) with water or in plain water. The reactions proceeded smoothly even in water to give the corresponding polyesters, although the rate of the reaction decreased gradually with increasing water in the mixture. Polymers prepared in the aqueous solution had higher molecular weights $\left(M_{n}, 7700-9200\right)$ than the polymers synthesized in DMSO $\left(M_{n}, 6100-6400\right)$.

KEY WORDS Water / Aqueous Solution / Polycondensation / Polyester / 1,8-Diazabicyclo[5.4.0]undec7-ene / Dicarboxylic Acids / Alkylene Dihalides
\end{abstract}

The careful removal of water is required in many cases of organic synthesis and polymer synthesis, because these reactions, especially ionic reactions, are strongly hindered or blocked by the presence of water. However, it seems that water and aqueous solution have great possibilities as reaction media from the viewpoint of incombustibility, safety, and economics in the laboratory and industry. Emulsion polymerization and suspension polymerization of hydrophobic monomers such as vinyl chloride, vinyl acetate, styrene, ethyl acrylate, and butadiene with radical initiators in water as a reaction medium have long been carried out for the preparation of polymers in the laboratory and industry.

Recently, phase transfer catalysis between the organic phase and the aqueous phase as well as the solid phase have been used conveniently for various organic reactions ${ }^{1}$ such as substitution, elimination, and oxidation reactions. These heterogeneous reaction systems were extended to polymer synthesis ${ }^{2}$ and chemical modification of polymers ${ }^{3}$ under mild conditions. However, the substitution reaction of pendant nucleophilic groups such as carboxylate and phenolate anions in polymers with low molecular weight alkyl halides does not proceed even in the presence of phase transfer catalysts. ${ }^{4,5}$ Nishikubo et al. reported $^{4,6}$ recently that the reaction of pendant carboxyl group in poly(methacrylic acid) with various alkyl halides proceed very smoothly to give the corresponding poly(methacrylic ester)s using 1,8-diazabicyclo[5.4.0] undec-7-ene (DBU) as a base in dimethyl sulfoxide (DMSO) and $N, N$-dimethylformamide (DMF) under mild reaction conditions. More recently, it was also found ${ }^{7}$ that the esterification reaction of poly(methacrylic acid) with alkyl halides proceeds quantitatively using DBU in aqueous solution or even in water under mild reaction conditions.

Polyesters are usually prepared ${ }^{8}$ by a solution polymerization of dicarboxylic acid chlorides with difunctional alcohols or phenols in anhydrous organic solvent or an interfacial polymerization between dicarboxylic acid chlorides in organic layer and difunctional alcohols or

\footnotetext{
$\dagger$ To whom all correspondence should be addressed.
}

phenols in aqueous layer. These reactions are carried out under mild conditions. However, the activated dicarboxylic acid chlorides are essentially unstable to the moisture in the air and to water in the solution. Imai et al. reported ${ }^{9}$ the synthesis of polyesters by the reaction of potassium salt of dicarboxylic acids with alkylene dihalides using phase-transfer catalysis (PTC), although, the reaction performed at relatively high temperature. The authors reported ${ }^{10}$ the synthesis of polyesters by the polycondensation of alkylene dihalides with dicarboxylic acids using DBU method. The reaction with DBU is a very simple and convenient for the synthesis of polyesters because preparation and purification of the activated dicarboxylic acids are not necessary, and the polycondensation proceeds under mild condition.

From these back grounds, it is reasonable to consider for us that aqueous solution and water should be useful for polymer synthesis. This paper reports the synthesis of polyesters by reactions of dicarboxylic acids with alkylene dihalides using DBU as a base in aqueous solution and plain water.

\section{EXPERIMENTAL}

\section{Materials}

Solvents were purified in the standard way before use. DBU was used after distillation using $\mathrm{CaH}_{2}$. Sodium carbonate $\left(\mathrm{Na}_{2} \mathrm{CO}_{3}\right)$, potassium carbonate $\left(\mathrm{K}_{2} \mathrm{CO}_{3}\right)$, 18-crown-6, and 15-crown-5 were used without further purification. $m$-Xylylene dibromide (MXDB) was recrystallized from acetone. $p$-Xylylene dibromide (PXDB) was recrystallized from chloroform. 1,4-Dichlorobutane (DCB), 1,4-dibromobutane (DBB), and 1,4-diiodobutane (DIB) were purified by distillation. Succinic acid (SCA) and adipic acid (AA) were recrystallized from water. Sebacic acid (SBA), phthalic acid (PHA), and isophthalic acid (IPA) were recrystallized from methanol.

\section{Measurements}

Infrared (IR) spectra were measured on a JASCO Model IR-700 spectrometer. ${ }^{1} \mathrm{H}$ NMR spectra were recorded on JEOL Models JNM EX-90 (90 MHz) and 
JNM FX-200 $(200 \mathrm{MHz})$ instruments in DMSO- $d_{6}$ or $\mathrm{CDCl}_{3}$ using tetramethylsilane as the standard. Molecular weights of the polymers were estimated by gel permeation chromatography (GPC) using a Tosoh Model HLC-8020 GPC equipped with a refractive index detector using TSKgel GMHKL columns (eluent: DMF, calibrated with narrow molecular weight polystyrene standards).

\section{Typical Procedure for the Polycondensation of Dicarbox- ylic Acid with Alkylene Dihalide Using DBU \\ Polycondensation in DMSO. AA $(0.365 \mathrm{~g} ; 2.5 \mathrm{mmol})$} was dissolved in DMSO $(2 \mathrm{~mL})$, and DBU $(0.761 \mathrm{~g}$; $5 \mathrm{mmol})$ were added with stirring. To the AA-DBU salt solution, MXDB $(0.660 \mathrm{~g} ; 2.5 \mathrm{mmol})$ dissolved in DMSO $(3 \mathrm{~mL})$ was added. The reaction mixture was stirred at $30^{\circ} \mathrm{C}$ for $12 \mathrm{~h}$ and poured into $100 \mathrm{~mL}$ of methanol. The resulting polymer $(\mathrm{P}-1)$ was purified by reprecipitation from chloroform solution into methanol, and finally dried at $60^{\circ} \mathrm{C}$ in vacuo. The yield of polymer was $0.378 \mathrm{~g}(61 \%)$. The number average molecular weight $\left(M_{n}\right)$ of the polymer determined by GPC was $6300\left(M_{w}\right)$ $\left.M_{n}, 1.39\right)$. IR (film, $\left.\mathrm{cm}^{-1}\right) ; 1735\left(v_{\mathrm{C}=\mathrm{o}}\right), 1238,1164$ $\left(v_{\mathrm{C}-\mathrm{O}-\mathrm{C}}\right) .{ }^{1} \mathrm{H}$ NMR $\left(200 \mathrm{MHz}, \mathrm{CDCl}_{3}, \mathrm{TMS}\right) ; \delta(\mathrm{ppm})$ : $1.55-1.78\left(\mathrm{~m}, 4.0 \mathrm{H},-\mathrm{CH}_{2}-\mathrm{CH}_{2}-\right), 2.20-2.50(\mathrm{~m}, 4.0 \mathrm{H}$, $\left.-\mathrm{CH}_{2}-\mathrm{CO}-\right), 5.10\left(\mathrm{~s}, 4.0 \mathrm{H},-\mathrm{CH}_{2}-\mathrm{O}-\mathrm{CO}-\right), 7.10-7.35$ (m, $4 \mathrm{H}$, aromatic protons).

Polycondensation in Water. AA $(0.365 \mathrm{~g} ; 2.5 \mathrm{mmol})$ and DBU $(0.761 \mathrm{~g} ; 5 \mathrm{mmol})$ were added to water $(5 \mathrm{~mL})$ with stirring. To the AA-DBU salt solution, MXDB $(0.660 \mathrm{~g} ; 2.5 \mathrm{mmol})$ was added. The reaction mixture was stirred at $50^{\circ} \mathrm{C}$ for $96 \mathrm{~h}$ and then poured into methanol $(100 \mathrm{~mL})$. The resulting polymer was purified by reprecipitation from chloroform solution into methanol, and finally dried at $60^{\circ} \mathrm{C}$ in vacuo. The yield of polymer was $0.192 \mathrm{~g} \mathrm{(31 \% ).} \mathrm{The} M_{n}$ of the resulting polymer determined by GPC was $7000\left(M_{w} / M_{n}, 1.31\right)$.

\section{RESULTS AND DISCUSSION}

Reaction of AA and MXDB was carried out using DBU as a base in DMSO, ${ }^{9}$ various aqueous solutions of DMSO and water with different volume ratios, and water (Scheme 1). Although the reaction proceeded homogeneously in DMSO, it took place heterogeneously in mixed solvents or plain water. In the heterogeneous reaction system, the resulting polymers precipitated to the bottom of the reaction flask as pasty solids.

As summarized in Table I, polymer P-1 was obtained with $56-61 \%$ yields in DMSO at $30^{\circ} \mathrm{C}$ for $12-72 \mathrm{~h}$. The yields of P-1 were $55-63 \%$ when the reactions were carried out in a mixed solvent of DMSO (80 vol\%) and water $(20 \mathrm{vol} \%)$ under the same conditions. It seems that yield of P-1 was not affected by the reaction time when the reaction was performed in DMSO or the mixed solvent containing small amount of water as above conditions.
When the reaction was performed in a mixed solvent of DMSO (50 vol\%) and water $(50 \mathrm{vol} \%)$ at $30^{\circ} \mathrm{C}$, yields of P-1 were $27,34,48$, and $45 \%$ at $12,24,48$, and $72 \mathrm{~h}$, respectively. When the reaction was carried out in the plain water at $50^{\circ} \mathrm{C}$ for $24-96 \mathrm{~h}$, the yield of $\mathrm{P}-1$ increased with reaction time, and P-1 was obtained with $31 \%$ yield at $96 \mathrm{~h}$. These results means that the reaction of AA with MXDB thus proceeds using DBU in a mixed solvent of DMSO with water or even water in heterogeneous reaction system, although the reaction rate decreased gradually with increasing water as the reaction medium.

As shown in Table I, $M_{n} \mathrm{~s}$ of the resulting polymers P-1 prepared in DMSO were 6100-6400. Polymers P-1 prepared in the mixed solvents of DMSO (80) with water (20), and DMSO (50) with water (50) were 9000-9200, and $7700-8700$, respectively. It is clear that the polymers prepared in the mixed solvents have higher $M_{n}$ than the polymers synthesized in DMSO. Nishikubo et al. reported that DMSO is a suitable solvent for the polycondensation of dicarboxylic acids with alkylene dihalides using DBU. ${ }^{10}$ However, the oxidation reaction of halomethyl group by DMSO is also known. ${ }^{11}$ Therefore, it seems that the oxidation reaction occurs slightly as a side reaction, when the reaction is performed homogeneously in DMSO. On the other hand, when the reaction was carried out in the heterogeneous system in the mixed solvents of DMSO with water, the side reaction was blocked by the presence of large amounts of water. The resulting polymers precipitated as pasty solids in the

Table I. Synthesis of polymer P-1 by reactions of AA with MXDB using DBU in mixed solvents of DMSO and water ${ }^{\mathrm{a}}$

\begin{tabular}{|c|c|c|c|c|}
\hline Solv. & Time & Yield & $M_{n}$ & \\
\hline (DMSO/Water) & $\mathrm{h}$ & $\%^{b}$ & $\times 10^{-3 c}$ & \\
\hline$(10 / 0)$ & 12 & 61 & 6.3 & 1.39 \\
\hline$(10 / 0)$ & 24 & 56 & 6.2 & 1.45 \\
\hline$(10 / 0)$ & 48 & 57 & 6.4 & 1.44 \\
\hline$(10 / 0)$ & 72 & 58 & 6.1 & 1.41 \\
\hline$(8 / 2)$ & 12 & 55 & 9.1 & 1.67 \\
\hline$(8 / 2)$ & 24 & 59 & 9.0 & 1.61 \\
\hline$(8 / 2)$ & 48 & 63 & 9.2 & 1.88 \\
\hline$(8 / 2)$ & 72 & 59 & 9.2 & 1.88 \\
\hline$(5 / 5)$ & 12 & 27 & 8.0 & 1.49 \\
\hline$(5 / 5)$ & 24 & 34 & 7.7 & 1.65 \\
\hline$(5 / 5)$ & 48 & 48 & 8.7 & 1.57 \\
\hline$(5 / 5)$ & 72 & 45 & 7.8 & 1.50 \\
\hline$(0 / 10)$ & 72 & trace & - & - \\
\hline$(0 / 10)^{d}$ & 24 & 10 & 8.8 & 1.38 \\
\hline$(0 / 10)^{d}$ & 48 & 26 & 8.5 & 1.32 \\
\hline$(0 / 10)^{d}$ & 96 & 31 & 7.0 & 1.31 \\
\hline$(0 / 10)^{d}$ & 168 & 28 & 7.3 & 1.40 \\
\hline$(0 / 10)^{d}$ & 240 & 30 & 6.4 & 1.37 \\
\hline
\end{tabular}

${ }^{\text {a }}$ Reaction was carried out with AA $(2.5 \mathrm{mmol})$ and MXDB (2.5 $\mathrm{mmol})$ using DBU $(5 \mathrm{mmol})$ in solvent $(5 \mathrm{~mL})$ at $30^{\circ} \mathrm{C}$. ${ }^{\text {b }}$ Insoluble parts in $\mathrm{MeOH}$. ${ }^{\mathrm{c}}$ Estimated by GPC based on polystyrene standards. ${ }^{\mathrm{d}}$ Reaction was carried out at $50^{\circ} \mathrm{C}$.

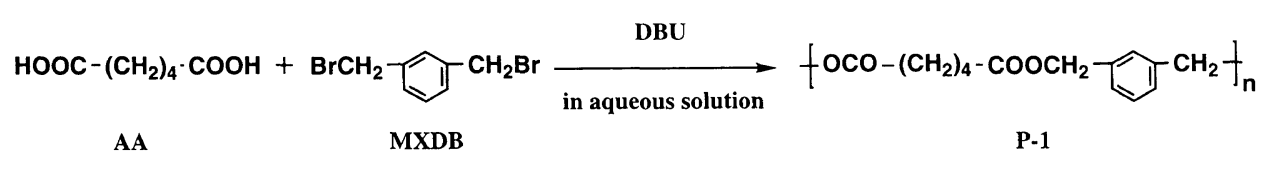

Scheme 1. 


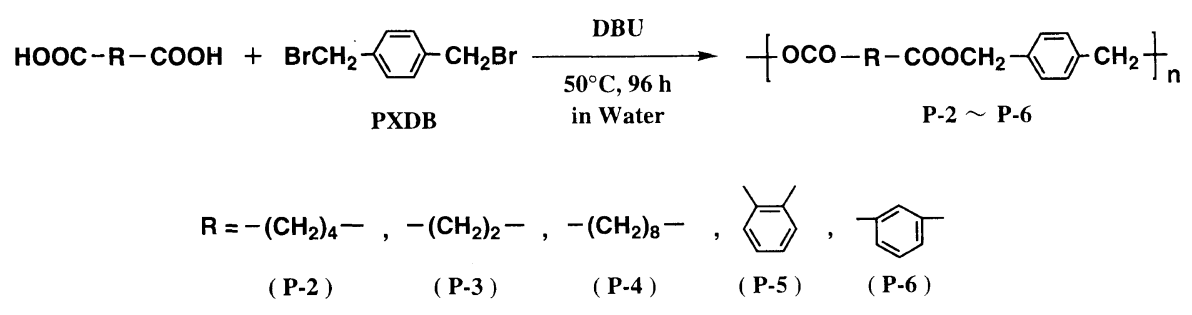

Scheme 2.

Table II. Synthesis of polymer P-2 by reactions of AA with PXDB using DBU in mixed solvent of DMSO and water ${ }^{\mathrm{a}}$

\begin{tabular}{|c|c|c|c|c|c|}
\hline Solv. & Ras & Time & Yield & $M_{n}$ & $M / M^{\mathrm{c}}$ \\
\hline (DMSO/Water) & & $\mathrm{h}$ & $\%^{b}$ & $\times 10^{-3 c}$ & \\
\hline$(10 / 0)$ & DBU & 12 & 77 & 7.7 & 1.66 \\
\hline$(10 / 0)$ & DBU & 24 & 81 & 7.9 & 1.62 \\
\hline$(10 / 0)$ & DBU & 48 & 86 & 7.5 & 1.78 \\
\hline$(10 / 0)$ & DBU & 72 & 88 & 9.9 & 1.78 \\
\hline$(8 / 2)$ & DBU & 12 & 74 & 5.1 & 1.60 \\
\hline$(8 / 2)$ & DBU & 24 & 72 & 6.0 & 1.77 \\
\hline$(8 / 2)$ & DBU & 48 & 75 & 6.0 & 1.75 \\
\hline$(8 / 2)$ & DBU & 72 & 74 & 6.0 & 1.79 \\
\hline$(5 / 5)$ & DBU & 12 & 13 & 5.6 & 1.59 \\
\hline$(5 / 5)$ & DBU & 24 & 29 & 5.9 & 1.56 \\
\hline$(5 / 5)$ & DBU & 48 & 55 & 6.0 & 1.53 \\
\hline$(5 / 5)$ & $\mathrm{DBU}$ & 72 & 61 & 6.1 & 1.56 \\
\hline$(0 / 10)$ & DBU & 72 & 0 & - & - \\
\hline$(0 / 10)^{d}$ & DBU & 48 & 31 & 8.2 & 1.63 \\
\hline$(0 / 10)^{d}$ & DBU & 96 & 52 & 8.6 & 1.58 \\
\hline$(0 / 10)^{d}$ & DBU & 168 & 55 & 8.3 & 1.57 \\
\hline$(0 / 10)^{d}$ & $\mathrm{Na}_{2} \mathrm{CO}_{3} / 15-\mathrm{C}-5$ & 96 & 0 & - & - \\
\hline$(0 / 10)^{d}$ & $\mathrm{~K}_{2} \mathrm{CO}_{3} / 18-\mathrm{C}-6$ & 96 & 0 & - & - \\
\hline
\end{tabular}

${ }^{a}$ Reaction was carried out with AA $(2.5 \mathrm{mmol})$ and MXDB $(2.5 \mathrm{mmol})$ using DBU $(5 \mathrm{mmol})$ in solvent $(5 \mathrm{~mL})$ at $30^{\circ} \mathrm{C}$. ${ }^{\mathrm{b}}$ Insoluble parts in $\mathrm{MeOH} .{ }^{\mathrm{c}}$ Estimated by GPC based on polystyrene standards. ${ }^{\mathrm{d}}$ Reaction was carried out at $50^{\circ} \mathrm{C}$.

mixed solvents. Therefore, it seems that the concentrations of propagating terminals increase in the precipitated products. However, when the reaction was carried out in plain water, $M_{n}$ of the obtained polymers decreased gradually with increasing reaction time, although the yield of polymer increased gradually with time. Some hydrolysis of the resulting polyester thus may occur as a side reaction during the polycondensation between $\mathrm{AA}$ with MXDB in water for a long reaction time at $50^{\circ} \mathrm{C}$.

The polycondensation reaction of AA with PXDB was examined using DBU as a base. When the reaction was performed in DMSO, the reaction system was homogeneous at the initial stage, and then became heterogeneous to precipitate the resulting polymer with increasing reaction time. When the reaction was carried out in mixed solvent or water, the reaction proceeded heterogeneously in a liquid-solid two-phase system from the initial stage. In the reaction of AA with $\mathrm{PXDB}$, the precipitated polymer (P-2) was suspended in solution because it was not a pasty solid such as $\mathrm{P}-1$ but a powdery solid (Scheme 2).

As summarized in Table II, polymers P-2 were obtained in $77-88 \%$ yields in DMSO at $30^{\circ} \mathrm{C}$ for $12-$ $72 \mathrm{~h}$. When the reaction was carried out in the mixed solvent of DMSO $(80 \mathrm{vol} \%)$ with water $(20 \mathrm{vol} \%)$, the yields of polymer P-2 were $72-75 \%$. The apparent correlation between the yield and the reaction time was not found. Polymers P-2 were obtained with 13-61\% yields when the reaction was performed in the mixture of DMSO $(50 \mathrm{vol} \%)$ with water $(50 \mathrm{vol} \%)$ under the same reaction conditions, and the yield of the polymer increased remarkably with reaction time. The yield of polymer P-2 increased with reaction time when the reaction was carried out in the plain water at $50^{\circ} \mathrm{C}$, although polymer P-2 was not obtained at $30^{\circ} \mathrm{C}$ for $72 \mathrm{~h}$. The rate of the polycondensation of AA with PXDB may thus decrease by with increasing water.

Polymers P-2 prepared in DMSO have relatively higher $M_{n}$ s than the polymers prepared in the mixed solvents of DMSO with water under the same conditions, although polymers $\mathrm{P}-1$ prepared by the reaction of AA with MXDB in DMSO have lower $M_{n}$ s than the polymers obtained from the reaction in the mixed solvents of DMSO with water. It seems that the heterogeneous system in the reaction of AA with PXDB blocked effectively the oxidation of halomethyl groups as side reactions even in DMSO, although the oxidation reaction of haloalkyl groups was also blocked by the presence of much water.

When the reaction was carried out in plain water at $50^{\circ} \mathrm{C}$ for $48-168 \mathrm{~h}$, polymers P-2 with $M_{n}$ of 8200 8600 were prepared with $31-55 \%$ yields, although the polymer was not obtained in water at $30^{\circ} \mathrm{C}$ for $72 \mathrm{~h}$. Thus although the rate of polycondensation of dicarboxylic acid with alkylene dihalide in plain water is very slow, the reaction was enhanced by heating at appropriate temperature.

When inorganic bases such as $\mathrm{Na}_{2} \mathrm{CO}_{3}$ and $\mathrm{K}_{2} \mathrm{CO}_{3}$ with crown ethers were used in water, targeted polymers P-2 were not obtained. This suggests that the carboxylate anion paired with protonated DBU, a hydrophobic residue, has higher reactivity to alkylene dihalide than the carboxylate anion paired with alkaline metal cations which are relatively hydrophilic residues.

The polycondensation reactions of $\mathrm{AA}$ with various alkylene dihalides such as MXDB, PXDB, DCB, DBB, and DIB were performed using $\mathrm{DBU}$ in plain water at $50^{\circ} \mathrm{C}$ for $96 \mathrm{~h}$. The reactions of AA with DCB, DBB, and DIB proceeded in a liquid-liquid two-phase system consisting of an aqueous solution of AA and an organic layer based on DCB, DBB, or DIB. As shown in Table III, the corresponding polyesters were not synthesized by reactions of AA with alkylene dihalides'such as DCB, DBB, and DIB, although polymers $\mathrm{P}-1$ and $\mathrm{P}-2$ were obtained by reactions of AA with MXDB and with $\mathrm{PXDB}$, respectively, in water. This indicates that the reactivity of $\mathrm{DCB}, \mathrm{DBB}$, and $\mathrm{DIB}$ to dicarboxylic acid $\mathrm{AA}$ is lower than that of MXDB and PXDB. 
Table III. Synthsis of polymers by reactions of AA with various alkylene dihalide in water $^{\mathrm{a}}$

\begin{tabular}{|c|c|c|c|}
\hline \multirow{2}{*}{ Alkylene dihalides } & Yield & $M_{n}$ & \multirow{2}{*}{$M_{w} / M_{n}^{\mathrm{c}}$} \\
\hline & $\%{ }^{b}$ & $\times 10^{-3 \mathrm{c}}$ & \\
\hline MXDB & 31 & 7.0 & 1.31 \\
\hline PXDB & 52 & 8.6 & 1.58 \\
\hline DCB & 0 & - & - \\
\hline DBB & 0 & - & - \\
\hline DBI & 0 & - & - \\
\hline
\end{tabular}

a Reaction was carried out with AA $(2.5 \mathrm{mmol})$ and alkylene dihalide $(2.5 \mathrm{mmol})$ using $\mathrm{DBU}(5 \mathrm{mmol})$ in water at $50^{\circ} \mathrm{C}$ for $96 \mathrm{~h}$. ${ }^{b}$ Insoluble parts in $\mathrm{MeOH}$. ${ }^{\mathrm{c}}$ Estimated by GPC based on polystyrene standrds.

Table IV. Effects of the feed ratio on reactions of AA with PXDB $^{\mathrm{a}}$

\begin{tabular}{|c|c|c|c|}
\hline Feed ratio & Yield & $M_{n}$ & \\
\hline (AA/PXDB/DBU) & $\%{ }^{b}$ & $\times 10^{-3 d}$ & \\
\hline $1.00 / 1.00 / 2.00$ & 52 & 8.6 & 1.58 \\
\hline $1.00 / 1.05 / 2.00$ & 55 & 8.5 & 1.51 \\
\hline $1.00 / 1.00 / 2.10$ & 56 & 8.9 & 1.58 \\
\hline $1.00 / 1.05 / 2.10$ & $55(7)^{d}$ & 9.4 & 1.69 \\
\hline
\end{tabular}

${ }^{\text {a }}$ Reaction was carried out with AA $(2.5 \mathrm{mmol})$ and PXDB using $\mathrm{DBU}$ in water $(5 \mathrm{~mL})$ at $50^{\circ} \mathrm{C}$ for $96 \mathrm{~h}$. ' Insoluble parts in methanol. ${ }^{\mathrm{c}}$ Estimated by GPC based on polystyrene standards. ${ }^{\mathrm{d}}$ Insoluble parts in chloroform.

Effects of the feed ratios on the polycondensation of AA with PXDB using DBU as a base in water were examined at $50^{\circ} \mathrm{C}$ for $96 \mathrm{~h}$ (Table IV). Polymer P-2 with the highest molecular weight $\left(M_{n}: 9400\right)$ was obtained in $62 \%$ yield using small excess of DBU and PXDB. The product contained $7 \mathrm{wt} \%$ of insoluble parts in chloroform. The insoluble parts in chloroform were insoluble in acetone, ethyl acetate, Tetrahydrofuran (THF), DMSO, DMF, 1-methyl-2-pyrrolidinone (NMP), and toluene. The IR spectrum of the product showed the peak of $\mathrm{C}=\mathrm{O}$ stretching due to ester group at $1731 \mathrm{~cm}^{-1}$. The insoluble parts in the organic solvents were polyester with very high molecular weight.

Polycondensation of some dicarboxylic acids such as succinic acid (SCA), sebasic acid (SBA), phthalic acid (PHA), and isophthalic acid (IPA) with PXDB were performed using a small excess of DBU in water at $50^{\circ} \mathrm{C}$ for $96 \mathrm{~h}$ (Table V).

The polycondensations proceeded smoothly to give the corresponding polymers in $47-74 \%$ yields even in water under the mild conditions. When the polycondensation of SCA or IPA with PXDB was performed, the products included 4 or $6 \mathrm{wt} \%$ of insoluble parts in organic solvents, respectively. It seems that the insoluble parts in organic solvents were the corresponding polyesters with high molecular weight. The IR and ${ }^{1} \mathrm{H}$ NMR spectra of resulting polymers (P-1, P-2, P-4, P-5, and soluble parts in chloroform of P-3 and P-6) are summarized in Table VI. These spectral data suggest that the corresponding polyesters were synthesized by the polycondensation of certain dicarboxylic acid with MXDB and PXDB even in water.

From all the results, it may be concluded that both
Table V. Synthesis of various polymers by reactions of certain carboxylic acids with PXDB using DBU in water ${ }^{\mathrm{a}}$

\begin{tabular}{|c|c|c|c|c|}
\hline \multirow{2}{*}{$\begin{array}{c}\text { Polym. } \\
\text { No. }\end{array}$} & \multirow{2}{*}{$\mathrm{R}^{1}$} & Yield & $M_{n}$ & \multirow{2}{*}{$M_{w} / M_{n}{ }^{\mathrm{c}}$} \\
\hline & & $\%^{b}$ & $\times 10^{-3 c}$ & \\
\hline P-2 & $-\left(\mathrm{CH}_{2}\right)_{4}-$ & 56 & 8.9 & 1.58 \\
\hline P-3 & $-\left(\mathrm{CH}_{2}\right)_{2}-$ & $47(4)^{d}$ & 8.8 & 1.53 \\
\hline P-4 & $-\left(\mathrm{CH}_{2}\right)_{8}-$ & 74 & 6.5 & 1.45 \\
\hline P-5 & & 60 & 8.2 & 1.64 \\
\hline P-6 & & $58(6)^{d}$ & 6.6 & 1.45 \\
\hline
\end{tabular}

${ }^{a}$ Reaction was carried out with dicarboxylic acid $(2.5 \mathrm{mmol})$ and PXDB $(2.5 \mathrm{mmol})$ using DBU $(5.25 \mathrm{mmol})$ in water $(5 \mathrm{~mL})$ at $50^{\circ} \mathrm{C}$ for $96 \mathrm{~h} .{ }^{\mathrm{b}}$ Insoluble parts in methanol. ${ }^{\mathrm{c}}$ Estimated by GPC based on polystyrene standards. ${ }^{\mathrm{d}}$ Insoluble parts in chloroform.

Table VI. IR and ${ }^{1} \mathrm{H}$ NMR spectra of polymers

\begin{tabular}{|c|c|c|}
\hline \multirow{2}{*}{$\begin{array}{l}\text { Polym. } \\
\text { No. }\end{array}$} & \multirow{2}{*}{$\frac{\text { IR }}{\text { Film } / \mathrm{cm}^{-1}}$} & ${ }^{1} \mathrm{H}$ NMR \\
\hline & & $200 \mathrm{MHz}, \mathrm{CDCl}_{3}, \mathrm{TMS}$ \\
\hline P-1 & $\begin{array}{l}1735\left(v_{\mathrm{C}=\mathrm{o}}\right) \\
1238,1164\left(v_{\mathrm{C}-\mathrm{o}-\mathrm{c}}\right)\end{array}$ & $\begin{aligned} \delta(\mathrm{ppm})= & 1.55-1.78\left(\mathrm{~m}, 4.0 \mathrm{H},-\mathrm{CH}_{2}-\right. \\
& \left.\mathrm{CH}_{2}\right), 2.20-2.50(\mathrm{~m}, 4.0 \mathrm{H}, \\
& \left.\mathrm{CH}_{2}-\mathrm{CO}\right), 5.10(\mathrm{~s}, 4.0 \mathrm{H}, \\
& \left.-\mathrm{CH}_{2}-\mathrm{O}-\right), 7.10-7.35(\mathrm{~m}, 4 \mathrm{H}, \\
& \text { aromatic protons })\end{aligned}$ \\
\hline P-2 & $\begin{array}{l}1736\left(v_{\mathrm{C}=\mathrm{o}}\right) \\
1259,1171\left(v_{\mathrm{C}-\mathrm{o}-\mathrm{C}}\right)\end{array}$ & $\begin{array}{l}1.42-1.80\left(\mathrm{~m}, 4.0 \mathrm{H},-\mathrm{CH}_{2}-\right. \\
\left.\mathrm{CH}_{2}\right), 2.20-2.50(\mathrm{~m}, 4.0 \mathrm{H}, \\
\left.\mathrm{CH}_{2}-\mathrm{CO}\right), 5.12\left(\mathrm{~s}, 4.0 \mathrm{H},-\mathrm{CH}_{2}-\right. \\
\mathrm{O}-), 7.38(\mathrm{~s}, 4 \mathrm{H} \text {, aromatic } \\
\text { protons })\end{array}$ \\
\hline P-3 & $\begin{array}{l}1730\left(v_{\mathrm{C}=\mathrm{o}}\right) \\
1267,1151\left(v_{\mathrm{C}-\mathrm{o}-\mathrm{C}}\right)\end{array}$ & $\begin{array}{l}2.68\left(\mathrm{~s}, 4.0 \mathrm{H},-\mathrm{CH}_{2}-\mathrm{CO}-\right), 5.10 \\
\left(\mathrm{~s}, 4.0 \mathrm{H},-\mathrm{CH}_{2}-\mathrm{O}-\right), 7.32(\mathrm{~s}, 4 \mathrm{H}, \\
\text { aromatic protons })\end{array}$ \\
\hline P-4 & $\begin{array}{l}1738\left(v_{\mathrm{C}=\mathrm{o}}\right) \\
1220,1176\left(v_{\mathrm{C}-\mathrm{o}-\mathrm{C}}\right)\end{array}$ & $\begin{array}{l}1.05-1.75\left(\mathrm{~m}, 12 \mathrm{H},-\left(\mathrm{CH}_{2}\right)_{6}-\right), \\
2.20-2.50\left(\mathrm{~m}, 4.0 \mathrm{H}, \mathrm{CH}_{2} \mathrm{CO}\right), \\
5.10\left(\mathrm{~s}, 4.0 \mathrm{H},-\mathrm{CH}_{2}-\mathrm{O}-\right), 7.34 \\
\text { (s, } 4 \mathrm{H} \text {, aromatic protons) }\end{array}$ \\
\hline P-5 & $\begin{array}{l}1728\left(v_{\mathrm{C}=\mathrm{o}}\right) \\
1274,1121\left(v_{\mathrm{C}-\mathrm{o}-\mathrm{C}}\right)\end{array}$ & $\begin{array}{l}5.05-5.30\left(\mathrm{~m}, 4.0 \mathrm{H},-\mathrm{CH}_{2}-\right. \\
\mathrm{O}-), 7.15-7.80(\mathrm{~m}, 8 \mathrm{H}, \\
\text { aromatic protons })\end{array}$ \\
\hline P-6 & $\begin{array}{l}1731\left(v_{\mathrm{C}=\mathrm{o}}\right) \\
1270,1151\left(v_{\mathrm{C}-\mathrm{o}-\mathrm{C}}\right)\end{array}$ & $\begin{array}{l}5.38\left(\mathrm{~s}, 4.0 \mathrm{H},-\mathrm{CH}_{2}-\mathrm{O}-\right), 7.10- \\
8.80(\mathrm{~m}, 8 \mathrm{H}, \text { aromatic protons })\end{array}$ \\
\hline
\end{tabular}

water and the mixed solvent of DMSO with water are suitable reaction media for the polycondensation of dicarboxylic acids with alkylene dihalides using DBU as a base to produce the corresponding polyesters with under mild reaction conditions.

Acknowledgment. This work was supported by a grant from the Ministry of Education, Science, and Culture of Japan (No. 08455444), which is gratefully acknowledged.

\section{REFERENCES}

1. For example: (a) C. M. Starks, J. Am. Chem. Soc., 93, 195 (1971); (b) W. P. Wever and C. W. Gokel, "Phase Transfer Catalysis in Organic Synthesis," Springer-Verlag, Heidelberg, 1997; (c) C. M. Starks and C. Liotta, "Phase Transfer Catalysis," Academic Press, New York, N.Y., 1978.

2. For example: (a) Y. Imai, J. Macromol. Sci.-Chem., A15, 833 (1981); (b) A. K. Banthia, D. Lunsford, D. C. Webster, and J. E. McGrath, J. Macromol. Sci.-Chem., A15, 943 (1981); (c) Y. Imai, 
J. Syn. Org. Chem. Jpn., 42, 1095 (1984).

3. For example: (a) J. M. J. Frechet, J. Macromol. Sci.-Chem., A15, 877 (1981); (b) T. Nishikubo, Kobunshi, 35, 132 (1986); (c) T. Nishikubo and T. Iizawa, J. Syn. Org. Chem. Jpn., 51, 157 (1993).

4. T. Shimokawa and T. Nishikubo, Kobunshi Ronbunshu, 44, 641 (1987).

5. Y. F. Maa and S. H. Chen, Macromolecules, 22, 2036 (1989).

6. T. Nishikubo, T. Iizawa, A. Takahashi, and T. Shimokawa, $J$. Polym. Sci., Part A. Polym. Chem., 28, 105 (1990).

7. T. Nishikubo, A. Kameyama, Y. Yamada, and Y. Yoshida, $J$.
Polym. Sci., Part A., Polym. Chem., 34, 3531 (1996).

8. J. A. Moore Ed., "Macromolecular Synthesis," Col. 1, John Wiley, New York, N.Y., 1977, p 413.

9. M. Ueda, N. Sakai, and Y. Imai, Kobunshi Ronbunshu, 38, 443 (1981).

10. T. Nishikubo and K. Ozaki, Polym. J., 22, 1043 (1990).

11. (a) G. G. Darling and J. M. J. Frechet, J. Org. Chem., 51, 2207 (1986); (b) T. Shimokawa, H. Hatori, and T. Nishikubo, Kobunshi Ronbunshu, 49, 577 (1992). 